\title{
EL PATRIMONIO CULTURAL EDIFICADO SIN ROSTRO: DIAGNÓSTICO DE PERCEPCIÓN CIUDADANA, EL CASO DE SAN PEDRO SULA
}

\author{
Julio César Figueroa Castillo ${ }^{1}$ \\ Carrera de Mercadotecnia del Centro Universitario Tecnológico (CEUTEC), \\ Sede Central, San Pedro Sula
}

(Recibido: Julio, 2016/ Aceptado: Julio, 2017)

\section{Resumen}

El propósito de la presente investigación, está centrado en la descripción de las percepciones y actitudes de los habitantes de San Pedro Sula, en relación con la pérdida de su patrimonio.

Años de adoctrinamiento en el sistema educativo nacional para admirar la civilización maya del occidente y el legado de la colonia española convierten todo aquello perteneciente al siglo $\mathrm{XX}$ en algo normal o cotidiano y, por lo tanto, no digno de ningún orgullo y mucho menos, de esfuerzo en su preservación.

Esta investigación se realizó mediante la recopilación bibliográfica, recorrido de campo, encuestas, entrevistas a profundidad; es la esperanza del autor que esta iniciativa genere un efecto multiplicador y que en toda la vieja "ruta del banano", la de los puertos de Tela, Cortés, La Ceiba, Trujillo, en las antiguas estaciones ferroviarias de Potrerillos, Villanueva, Pimienta, Choloma, El Progreso, Olanchito, San Manuel, se despierte el deseo de proteger un legado visual que junto a la forma de ser, idiosincrasia de sus habitantes, música, gastronomía y tradición oral, forman parte de un país distinto al de teja, barro y maíz de los macizos montañosos del interior de la república, y que dicho espíritu sea celebrado en condiciones de igualdad con el legado colonial y precolombino.

Palabras Claves: Patrimonio Cultural, Ruta del Banano, Valle de Sula

\begin{abstract}
The purpose of this research is focused on the description of perceptions and attitudes of the citizens of San Pedro Sula, about the loss of their built heritage.

Years of indoctrination in the national educational system in admiration of the Mayan civilization of the West and the legacy of the Spanish colony, make everything belonging to the twentieth century anodyne and therefore not worthy of pride and much preservation effort.

This research was conducted by bibliographic compilation, fieldwork, surveys, in-depth interviews; the author's hope is that this initiative will generate a multiplier effect and awake the desire to protect a worthy visual legacy throughout the old "banana corridor", the port of Tela, Cortés, La Ceiba, Trujillo, the old railway stations Potrerillos, Villanueva, Pimienta,
\end{abstract}

\footnotetext{
${ }^{1}$ Autor para correspondencia. Email julio.figueroa@unitec.edu.hn
} 
Choloma, El Progreso, Olanchito, San Manuel, and that this heritage may be held by the country folks, on equal grounds with the colonial and pre-Columbian ones.

Keywords: Cultural Heritage, Banan Corridor, Sula Valley

\section{Introducción}

La arquitectura del período bananero de la república de Honduras, se distingue de manera muy importante de otros periodos, por su notable aportación al patrimonio cultural edificado de la ciudad de San Pedro Sula; que actualmente se percibe en el abandono, esto es así en todo el corredor del litoral atlántico y en el valle de Sula. El proceso de deterioro se ha incrementado especialmente desde los últimos años del siglo XX con el desarrollo, en la región, de nuevas inversiones en la década de los noventa, como maquiladoras y centros de llamadas telefónicas que crean presión en la demografía y en el uso del espacio urbano. Este cambio del paisaje es notorio en la ciudad de San Pedro Sula, por su rápido crecimiento y modernización.

Se prefiere hablar de período bananero para referirse a esa etapa de la historia de Honduras porque la expresión "República Bananera" tiene una connotación peyorativa e inexacta, además las "repúblicas bananeras" son más un recurso de la ficción literaria norteamericana del siglo XX, que una verdad histórica. De igual forma, es posible que el mismo trauma de la complicada experiencia de esta etapa histórica explique, hasta cierto grado, la falta de respeto por su legado, al tratarse de estructuras construidas por los estadounidenses y no por una idealizada cultura indígena o española. Habría que investigar si existe una falta de autoestima, que ayude a explicar el fenómeno de la destrucción indiscriminada de toda obra que date del período en cuestión.

Pocas personas en el país tienen conciencia del tema, la institución llamada a tener autoridad en el tema, es el Instituto Nacional de Antropología e Historia, así como el gobierno municipal; no obstante, la poca comunidad científica del país formada con sacrificio del erario público, o con becas y esfuerzo personal dedicada a la antropología e historia, ha concentrado casi todos sus esfuerzos siempre en el patrimonio precolombino y colonial, viéndose obligada a ello en parte por la falta de patrocinio ya sea público o privado para otro tipo de iniciativas, pero también por falta de interés de la comunidad, quizás por ello los esfuerzos se concentran en el patrimonio de los períodos señalados.

Del patrimonio del período bananero no existe mayor conciencia, otro aspecto es que el carácter monumental de la arquitectura precolombina y colonial resulta más interesante para el turista internacional, y por lo tanto hay mayor desembolso de fondos para estas investigaciones que para cualesquiera otras.

Una investigación de este tipo, viene a llenar un vacío en la historiografía nacional y local y aporta un grano de arena a la débil identidad de la región, se han realizado monografías de temas específicos, inventario de edificaciones, memorabilia y anecdotarios, pero no solo es necesario reconocer la existencia de este patrimonio y su valor histórico, si no también contestar las siguientes interrogantes ¿Qué opinan los habitantes de la ciudad sobre este patrimonio? ¿Cómo afecta este patrimonio a la imagen que tienen de sí mismos los habitantes de la ciudad? ¿Qué otras iniciativas se pueden instrumentar para la preservación de un legado que le da sabor a una ciudad 
para muchos concebida solo para trabajar? Ya que no solo se trata del conocimiento cuantitativo que se tiene del tema, si no la apreciación objetiva que los habitantes del territorio hacen del espacio que habitan, solo así se podría desarrollar una actitud similar a la de habitantes de ciudades históricas. Dentro del país puede mencionarse la antigua capital colonial, Comayagua, de la cual protegen y valoran su entorno, viéndolo como una oportunidad de calidad de vida, no como una imposición de una disposición gubernamental.

\section{Marco Teórico}

El interés de la sociedad por la preservación del patrimonio cultural deviene de la ilustración a finales del siglo XVIII, durante el proceso de construcción de entidades "Estados nacionales" en el contexto del romanticismo y el nacionalismo europeo, los Gobiernos y élites europeas promueven investigaciones y exploraciones tanto en su territorio como en los otros continentes, primero para forjar el discurso de una identidad nacional, luego por motivos de prestigio, enriqueciendo sus museos y colecciones privadas con el patrimonio de otras culturas. Guerrero (2011) afirma: "con el proceso de descolonización en el siglo XIX y siglo XX aparecen nuevos estados nacionales cuyas élites también buscan justificar la existencia de su nación con la investigación y documentación del propio pasado" (p.90). La gestión del patrimonio fue en su origen una iniciativa de las élites políticas y económicas con intereses políticos nacionalistas.

Durante el siglo XX, en el contexto de entreguerras se reconoce la existencia de una herencia tangible de la humanidad, a la que se le otorga categoría de bien superior.

Todo lo que existe es historia y puede ser patrimonializado. Ballart (1997) afirma que:

La noción de patrimonio aparece cuando un grupo humano toma un objeto del pasado y lo hace propio, el objeto en cuestión experimenta una honda transformación en la percepción del observador, de modo que de objeto "a secas" se convierta en objeto de patrimonio cultural. Los movimientos conservacionistas del medio cultural, reaccionan contra el modo de vida moderno, pragmático y consumista de la sociedad actual, que amenaza la permanencia de los vínculos históricos, poniendo en peligro de desaparición la herencia tangible del pasado (p.29).

Conviene también indagar continuamente sobre la percepción de los ciudadanos respecto a los procesos de revitalización para medir los impactos en las costumbres y valores arraigados, y los "conflictos por nuevas actividades y nuevos flujos de población" (Moreno, 2012). También existe el patrimonio "modesto" y hay que tomarlo en cuenta, se trata de edificaciones de menor valor. "Viviendas y paisajes urbanos que a pesar de no ser magníficos en sus proporciones o estética expresan la vida social de sus habitantes en una determinada época de la historia" (Ballart, 1997, p.36).

No obstante, en la práctica el patrimonio cultural ha sido "tradicionalmente identificado y protegido por profesionales de instituciones estatales con la desventaja de dar poca responsabilidad a las comunidades en el manejo de sus propios monumentos y paisajes culturales" (Europe Commission, 2015, p.8), la aplicación de políticas públicas de una forma vertical de arriba hacia abajo, diseñada por la élite y la academia, puede producir como efecto colateral una gestión del patrimonio que aliena al ciudadano del contexto que le rodea. 
Sin los ciudadanos no es posible la preservación del patrimonio cultural edificado, la vida diaria compartida de los ciudadanos es lo que constituye una ciudad, en palabras de Puig (2008): "una ciudad habitada está siempre más cuidada" (p.39). Si no hay implicación ciudadana, la ciudad no se preserva. "Si los ciudadanos no se sienten actores y protagonistas, los ciudadanos no podrán valorar su patrimonio cultural y su propia autoestima" (Puig, 2008, p.106).

Robert Shipley y Jason Kovacs (2007), nos dan tres razones por las que se debe analizar la participación ciudadana en la gestión y gobernanza del patrimonio cultural edificado: La importancia del patrimonio en el desarrollo económico de los pueblos; la forma como se asignan los fondos para su protección y la relación de la sociedad civil con estos procesos. Así mismo, señalan que en Norteamérica muchas veces la labor de proteger el patrimonio pertenece al municipio y se trabaja bajo la directriz de "ver a la comunidad como un todo antes de ver las partes individuales, no obstante, no se puede trasplantar la experiencia de Norteamérica y Europa a países con diferentes tradiciones, donde viejos patrones patriarcales tienen que ser desafiados" (Shipley y Kovacs, 2007, p.216). El análisis se debe adaptar a las circunstancias locales, finalmente, recomiendan principios de buena gobernanza del PNUD como herramienta para analizar las políticas de gestión patrimonial.

La investigación sobre la gestión patrimonial ha utilizado como instrumentos la investigación documental y bibliográfica, la encuesta personal, y la entrevista con expertos. Dichas herramientas se pueden complementar con otras, como el análisis FODA de fortalezas, oportunidades, debilidades y amenazas (Koorosh, 2012). Para revisar la documentación y leyes a nivel de ciudad, región y país, en el manejo del patrimonio, grupos focales o debates estructurados para encontrar hallazgos que puedan pasar desapercibidos para el investigador o grupo interventor, "la recolección de cuentos y memorias locales es útil para rescatar elementos de percepción y significados que las personas le dan a su entorno" (Zetti, 2010, p.231).

El uso de encuestas puede ser útil para encontrar hallazgos relevantes en cuanto a actitudes, valores, creencias y conocimiento del ciudadano con respecto a su patrimonio, para diagnosticar problemas de participación y vacíos en el sistema educativo, pudiendo aplicarse en una amplia gama de contextos culturales, por ejemplo.

Ladkin apunta que "la investigación cuantitativa debe ir refrendada por investigación cualitativa, a pesar de su flexibilidad la encuesta siempre debe ser contrastada con investigación documental y con entrevistas con expertos" (p.11). El instrumento encuesta permite darle voz a la opinión pública y puede generar hallazgos para la gestión del turismo. Las instituciones estatales y privadas encargadas de promover el turismo suelen utilizar imágenes y mensajes estereotípicos en su comunicación, mientras la población local puede brindar historias locales que dan valor a los sitios y les hacen ser distintivos, y dignos de visita.

Las historias e imágenes que el ciudadano provee usualmente son diferentes de las institucionales, esto permite una relación en dos direcciones, donde el profesional aprende lo que el ciudadano ve como valor patrimonial y a su vez el ciudadano puede percibir el conocimiento y la ardua labor que implica preservar y exhibir el patrimonio (Geser, 2012, p.24).

La recolección de historias e imágenes se pueden combinar con mapas sociales, en el mapa final se superponen los hallazgos extraídos junto con el grupo de participantes, el 
resultado se puede aplicar en la elaboración de recorridos culturales ya sea para fines de turismo o para educación patrimonial, como instrumento pedagógico para educación primaria o secundaria.

Concluye Olsson (2008) que un estudio cuantitativo tiene potencial para brindar conocimiento que de otro modo no sería visible para los gestores, pero debe ser complementado con técnicas cualitativas.

Tweed y Sutherland (2007) nos indican que hay pocos estudios acerca de las percepciones del patrimonio desde el punto de vista del ciudadano. Los mismos autores proponen un formato de encuesta de línea base, dicha línea base recolecta información de tres aspectos:

a) Percepción del ciudadano su conciencia, humor y familiaridad con el espacio patrimonial en estudio.

b) La actitud hacia un conjunto de acciones o propuestas de cambio específicas.

c) Información socioeconómica de la población, educación y demografía.

Es necesario contrastar la experiencia en países en vías de desarrollo donde "viejos patrones patriarcales tienen que ser desafiados" (Shipley y Kovacs, 2007, p.216). En la parte del estudio actitudinal es importante la aportación de Schiffman y Kanuk (2014) quienes nos dicen que:

Una actitud tiene tres componentes, lo que la persona conoce, lo que el conocimiento le hace sentir y lo que hará en base a lo que sabe y lo que siente, la actitud y por lo tanto la acción están ligadas al conocimiento y la percepción, el conocimiento toma la forma frecuentemente de creencias compartidas, el componente afectivo se manifiesta en sentimientos que pueden ser positivos o negativos, y la actitud son las acciones y comportamientos específicos (p.233).

En el estudio de las percepciones de los residentes se debe analizar el nivel de información que tienen, su percepción sobre el estado del patrimonio, las percepciones de los residentes en relación con oportunidades de participación en la comunidad local y los indicadores de desarrollo cultural sostenible, "con especial atención a la estimación de los niveles de participación de los residentes y su papel en su propio proceso de desarrollo" (Zetić, 2009, p.16).

En el contexto latinoamericano y centroamericano en particular, existe bibliografía del pasado precolombino y colonial, pero hay un notable vacío en el estudio del patrimonio republicano del siglo XX, la gestión patrimonial de América Latina ha sido centralizada cometiendo todos los errores posibles en la gestión de sus cascos históricos: "depauperación, gentrificación y mercantilización” (Reus, 2014, p.8). La depauperación ocurre cuando las clases medias y los negocios abandonan el casco antiguo, crece la inseguridad, la delincuencia, el abandono y el deterioro, la gentrificación se da cuando la zona termina siendo habitada por una población de edad mayor y a medida que pasa el tiempo los herederos no asumen responsabilidad por el mantenimiento de las estructuras y la mercantilización se produce en los casos en que habiendo una intervención de rescate, generalmente de parte del Estado, la puesta en valor del recurso patrimonial provoca la especulación inmobiliaria que expulsa a la población original de la zona y la convierte en un escaparate vacío de toda vida ritual. Por todo lo anterior sería interesante estudiar el componente actitudinal del ciudadano latinoamericano con respecto a su patrimonio republicano, como sujeto de su propio desarrollo y su relación y participación en las políticas públicas de gestión patrimonial, 
en sus distintas modalidades, normativa, financiación, educación e intervención directa (López, 2010, p.16).

\section{Metodología}

\subsection{Diseño}

Esta investigación es eminentemente empírica, utilizando entre otras técnicas de estudio, las siguientes:

a) Investigación documental, recopilación bibliográfica, en el apartado historia de San Pedro Sula, análisis de información demográfica de la Dirección Estadística Municipal.

b) Investigación de campo, método de encuesta y entrevista a profundidad, para diagnosticar conocimiento, actitudes y percepciones del ciudadano.

El tipo de diseño de la encuesta es conclusivo, descriptivo y transversal simple, conclusivo por que dará como resultado respuestas concretas a los objetivos planteados, descriptivo por que brindará descripción de las variables de investigación, transversal simple porque se tomará una muestra aleatoria simple una sola vez.

Para el aspecto de actitudes y percepción a investigar se hizo uso de la herramienta de la encuesta cara a cara, mediante encuestas para medir el nivel de conocimiento y grado de compromiso de los habitantes con el patrimonio de su ciudad.

El método encuesta no es suficiente para brindar una respuesta a los objetivos e hipótesis en estudio, porque solo se obtienen datos estadísticos que requieren una cuidadosa interpretación, por ello se hizo uso de técnicas cualitativas de investigación, se hizo uso de la herramienta cualitativa de la entrevista exhaustiva para investigar variables de interés en este estudio, como ser: la significancia histórica de las estructuras que se identifiquen.

La entrevista con expertos también es de utilidad para depurar el cuestionario a aplicar en el estudio, se entrevistó a personas que cuentan con conocimiento sobre la historia, arquitectura y vida social de la ciudad, en este grupo de entrevistados se incluye: personas de la tercera edad, maestros de secundaria jubilados y expertos que por su profesión conocen la historia viva de la ciudad, en particular arquitectos e ingenieros civiles.

Se realizó trabajo de campo que consistió en recorridos de campo en la zona objeto de estudio de todo el sector contenido en el primer anillo de circunvalación, el cual fue construido en 1940, prácticamente contiene el casco urbano completo de aquella época. Las herramientas de investigación se aplican entre enero y febrero de 2016.

\subsection{Población y muestra}

La muestra para la encuesta de este estudio fue de 200 encuestas, con un nivel de confianza del $95 \%$ y un margen de error del $7 \%$ la muestra ha sido determinada tomando en cuenta una población de 816,000 habitantes de los cuales el $38.16 \%$ vive en el casco urbano o sea 314,976, el resto vive en el área suburbana (siendo excluidos 
del estudio junto a la población rural del municipio), el 63\% son mayores de 15 años 198,435 personas, siendo considerados el tamaño y representatividad de la población en estudio, mayores de 15 años de todas las clases sociales residentes en el casco urbano de San Pedro Sula (DIEM, 2012).

Fórmula de la población infinita:

$$
n=\frac{Z^{2} p q}{e^{2}} \quad n=\frac{(1.96)^{2}(0.5)(0.5)}{(0.07)^{2}}
$$

$$
\mathrm{n}=196 \text { elementos a encuestar }
$$

La técnica de muestreo fue probabilística, estratificada (estrato 1 noroeste, estrato 2 suroeste, estrato 2 sureste, estrato 4 noreste) y por conglomerados (barrio y colonia en estrato urbano). Se tienen los siguientes datos demográficos de la ciudad (DIEM, 2013).

En esta tabla se muestra como está repartido el $38.16 \%$ de la población que vive en el casco urbano de San Pedro Sula por zona, de 816000, 38.16 \% vive en el área urbana es decir 314,976 personas.

Tabla 1. Población urbana por zona

\begin{tabular}{|c|c|}
\hline Zona & $\%$ de habitantes por zona \\
\hline Noroeste & $16.66 \%$ \\
\hline Noreste & $8.1 \%$ \\
\hline Suroeste & $2.8 \%$ \\
\hline Sureste & $10.6 \%$ \\
\hline
\end{tabular}

Fuente: DIEM (2014). Sistema de Indicadores Socio-Demográficos San Pedro Sula. Recuperado el 16 de 01 de 2015, de DIEM: http://www.infohn.com/sisde/home.htm

Tabla 2. Porcentaje de población por sector en la zona urbana

\begin{tabular}{|l|l|}
\hline Total Habitantes SPS casco urbano mayores de 15 años & 198,435 \\
\hline Noroeste & $44 \%$ \\
\hline Noreste & $21 \%$ \\
\hline Suroeste & $7 \%$ \\
\hline Sureste & $28 \%$ \\
\hline
\end{tabular}

Fuente: Elaboración Propia 
Tabla 3. Tamaño de muestra y estratificación

\begin{tabular}{|l|l|}
\hline Zona & Elementos a encuestar por zona \\
\hline Noroeste & 88 \\
\hline Noreste & 42 \\
\hline Suroeste & 14 \\
\hline Sureste & 56 \\
\hline
\end{tabular}

Fuente: Elaboración Propia

\subsection{Variables}

Las variables a evaluar en la participación ciudadana en la protección del patrimonio cultural edificado de Honduras fueron:

a) Nivel de conocimiento de los habitantes de San Pedro Sula acerca del patrimonio cultural edificado de la ciudad.

b) Percepción de los habitantes de San Pedro Sula acerca del patrimonio cultural edificado de la ciudad.

c) Grado de interés de los habitantes de San Pedro Sula acerca del patrimonio cultural edificado de la ciudad.

d) Actitud de los habitantes de San Pedro Sula hacia el patrimonio cultural edificado de la ciudad.

\subsubsection{Cruce de variables}

- Edad cruzada con conocimiento de los habitantes de San Pedro Sula acerca del patrimonio de su ciudad.

- Sexo con conocimiento de los habitantes de San Pedro Sula acerca del patrimonio de su ciudad.

- Zona de residencia con grado de compromiso de los habitantes de la ciudad con el patrimonio de su ciudad.

- Edad cruzada con grado de compromiso de los habitantes de la ciudad con el patrimonio de su ciudad.

- Sexo con grado de compromiso de los habitantes de la ciudad con el patrimonio de su ciudad.

- Zona de residencia con grado de compromiso de los habitantes de la ciudad con el patrimonio de su ciudad.

Se realizó trabajo de gabinete para evaluar los resultados de la recopilación bibliográfica y recorrido de campo. Los datos de las encuestas fueron tabulados en el programa estadístico SPSS, se realizó análisis de frecuencias univariado de las principales variables de interés y cruce multivariado entre las variables que se consideró pertinente cruzar. Siendo las variables a cruzar: edad, zona de residencia, sexo, grado de conocimiento del patrimonio de la ciudad, grado de interés en dicho patrimonio. 
El análisis estadístico del grado de significancia de estas variables se hizo con el software SPSS, siendo los indicadores a utilizar en el caso de las variables sexo y zona de residencia el análisis de Chi cuadrado, por tratarse de datos no métricos, y en los cruces que involucraron la edad, se usó regresión lineal por ser datos de tipo métrico.

Los datos generados de la entrevista a profundidad fueron analizados mediante transcripción e interpretación de los datos a criterio o juicio del investigador.

\subsection{Preguntas de investigación}

1) ¿Qué grado de conocimiento ostentan los habitantes de la ciudad de San Pedro Sula en lo referente al patrimonio cultural edificado?

2) ¿Qué percepciones tienen los habitantes de San Pedro Sula, respecto a su patrimonio cultural edificado?

3) ¿Qué rasgos predominan en las actitudes de los habitantes de San Pedro Sula, con relación a su patrimonio cultural edificado?

\subsection{Hipótesis general}

Mediante la adecuada caracterización de las políticas públicas; que influyen de una manera determinante en las percepciones y actitudes del ciudadano respecto al patrimonio cultural edificado de la ciudad de San Pedro Sula; se podrán caracterizar y proponer acciones tendientes a mejorar el interés ciudadano por la preservación de dicho patrimonio.

\subsection{Hipótesis secundaria}

Las políticas públicas del Estado de Honduras para la protección del patrimonio cultural edificado no son incluyentes, y tienen déficit en componentes de participación ciudadana, lo cual genera problemas de identidad, conocimiento, percepción y actitud en la ciudad de San Pedro Sula, afectando el patrimonio cultural edificado de la ciudad.

\subsection{Delimitación zona de estudio}

En el casco urbano de la ciudad de San Pedro Sula, siendo la zona de estudio el perímetro delimitado por el primer anillo de circunvalación, casco antiguo de la ciudad de San pedro Sula. La población objeto de estudio; los habitantes de la zona urbana de San pedro Sula, sector noroeste, suroeste, sureste y noreste; la investigación se realiza en el cuarto trimestre del año 2016.

El ámbito de actuación de este estudio se remite al circuito encerrado dentro de la avenida circunvalación, primer anillo de circunvalación de la ciudad construido en la década de 1940, se toma como zona de delimitación del área de estudio, ya que encierra dentro de sí la ciudad antigua, como se muestra en el mapa de la zona de estudio y en la fotografía aérea cortesía del museo de antropología e historia del valle de Sula (ver anexos). 
El tipo de instalaciones a tomar en cuenta, incluye edificios gubernamentales, casas particulares, comercios, destacando toda aquella obra realizada por el arquitecto Héctor Bustillo Oliva que ayudó a definir y construir una época.

El circuito dentro de la avenida circunvalación, se divide en dos mitades por la primera calle de este a oeste, prácticamente contiene la "ciudad vieja" de San Pedro Sula, fuera de sus linderos se da la expansión de nuevas zonas para urbanización.

\section{Resultados}

\subsection{Situación del patrimonio de la ciudad}

En general, las estructuras que están en uso se encuentran en buenas condiciones, el problema es la contaminación visual y modificaciones modernas a las fachadas, estos problemas se encuentran más que nada en las viviendas, no en las construcciones de uso gubernamental o comercial, siendo a su vez mínima la cantidad de viviendas en abandono o parcialmente destruidas. En definitiva, la preocupación es por todo lo que se ha perdido y que sigue desapareciendo día a día.

Dentro de lo que se ha perdido, se pueden enumerar las siguientes edificaciones: antiguo cabildo, antiguo cuartel y la primera iglesia de la ciudad; todos ellos alrededor del parque central, estas construcciones eran sencillas y poco estéticas, fueron reemplazadas por la actual alcaldía y catedral, mientras que donde se encontraba el cuartel hoy están el Hotel Sula y el Banco Atlántida (Stassano, 1997).

Los edificios de ladrillo construidos durante la administración del dictador Carías Andino y de Juan Manuel Gálvez (de 1932 a 1954), aún se encuentran en pie, las pérdidas más significativas se encuentran en las viejas casas y mansiones de madera, la casa Quiroz y la casa Castillo Nuila, ambas en el sector suroeste, se cuentan entre las más llamativas e imponentes que se perdieron, la principal razón puede ser el coste de mantenimiento de las construcciones de madera y la pérdida de habilidad y destreza entre los maestros de obra y albañiles en el trabajo de construcciones de madera, a medida que aumentó el uso del cemento en las construcciones, desde la década del 60, cuando se inauguraron las primeras plantas cementeras del país.

Otra pérdida significativa fue el comercio de Manuel Siu, ubicado en el sector sureste, para dar paso a una construcción moderna, el comercio de dicho lugar fue sitio de referencia en la ciudad y un ejemplo típico de construcción comercial en la etapa bananera del país (Stassano, 1997, p.100).

Los lugares emblemáticos de la ciudad son: el parque central, el edificio de la municipalidad, la catedral, el museo metropolitano, el museo de la naturaleza y el ferrocarril nacional, nótese la importancia de las construcciones "monumentales" en la mente de las personas, muchos de los edificios anteriormente mencionados no son precisamente históricos, si no que su construcción data de los años setenta del siglo pasado, sin embargo en la mente de las personas es lo imponente, lo más grande lo que viene a ser representativo y significativo. Es difícil, por ejemplo, que un habitante de la ciudad, sea éste migrante o no, no reconozca el edificio del ferrocarril nacional, si este se encuentra ubicado en la primera calle que recorre la ciudad de este a oeste y sirve de línea divisoria de la ciudad teniendo un elevado tráfico. De esta manera es lo más visible 
lo que queda en el imaginario colectivo, no necesariamente lo más antiguo o memorable desde el punto de vista arquitectónico, no obstante; los lugares emblemáticos vendrían a ser más, pero es probable que la gente no los conozca.

El parque central Luis Alonso Barahona en sí es uno de los lugares más reconocidos por el habitante y el visitante, así como su quiosco que data del año 1924, en este caso, al hacer un sondeo, la mayor observación que hacen las personas es la recuperación de ambos, ya que en el pasado eran epicentro de continuas actividades culturales y lamentablemente hoy en día se les considera sitios peligrosos, sitios de actividad de vagos y malvivientes. El deterioro no es tan grave y las modificaciones que han recibido no son tan traumáticas, lo que se extraña es la vida cívica que les caracterizaba, la seguridad es una preocupación primordial y constante en el que ha venido a ser conocido como el tercer país más violento de América Latina y San Pedro Sula, la ciudad más peligrosa del país, aunque buena parte de esa delincuencia no es delincuencia común, si no crimen organizado (narcotráfico).

Entre otros sitios o edificios se cuenta, la municipalidad construida por el arquitecto Héctor Bustillo Oliva, el edificio de Gobernación y justicia, la estatua del general Francisco Morazán en el boulevard del mismo nombre y que data del año 1922, el barrio Guamilito con aproximadamente una docena de casas representativas de la época de interés para este estudio, el mercado del mismo nombre y en el mismo barrio, el ya mencionado edificio del ferrocarril nacional, el edificio del Banco Atlántida construido en 1928 y ubicado en la 3 avenida (banco Atlántida es uno de los más antiguos de la zona norte de la república y sus edificaciones se cuentan entre las más antiguas de las ciudades del litoral siguiendo las mismas líneas arquitectónicas en todas sus sedes originales), la Logia masónica (obra del maestro José Canelo) de "molduras decorativas repetitivas, pero armoniosas" (Stassano, 1997, p.30).

Siguiendo con un repaso no somero de lugares emblemáticos de la ciudad, se cuenta el Bvd Lempira, construido entre 1927 y 1929, con una estatua del cacique indígena del mismo nombre, al menos una docena de casas de la ya mencionada primera calle, principal eje de la ciudad y su historia, la escuela Ramón Rosa, los dos museos, el de la naturaleza y el metropolitano de antropología e historia en la 3 avenida, 4 calle del barrio Guamilito, la catedral una construcción moderna iniciada en los años cuarenta y concluida en los años setenta, las instalaciones regionales del INTAE, San Pedro Sula.

Son de importancia también las casas, como la casa Córdoba Pineda, la casa del expresidente Miguel Paz Barahona, también casas comerciales, el cine Hispano, edificio de la droguería nacional, farmacia Barletta (todas de Héctor Bustillo Oliva) el local de comida rápida, Wendy's, en la calle peatonal frente al parque central.

Por último, se puede mencionar los viejos cines del centro de la ciudad, como el cine Hispano y el complejo Tropicana, son edificios modernos con apenas cuarenta años de antigüedad, pero forman parte del imaginario popular, se les empieza a ver con nostalgia, y el cambio de uso de sus instalaciones es visto con pesar por el público general, prácticamente pasaron a ser historia y parte del paisaje de la ciudad, a pesar de sus fachadas de estilo moderno.

Nótese como todos estos sitios se encuentran ubicados dentro de la avenida Circunvalación construida en 3 etapas aparentemente por iniciativa del arquitecto Héctor Bustillo Oliva en los años 1940, 1948, 1953, esto es durante las administraciones de facto de los presidentes Carías Andino y Juan Manuel Gálvez, en pleno apogeo de 
la economía de enclave bananero; dicha avenida contenía la mayor parte de la ciudad de aquella época.

\subsection{Resultados encuesta}

Pregunta 1: ¿Conoce algún edificio del patrimonio histórico de San Pedro Sula?

$\mathrm{Al}$ consultarle a los informantes si conocen un edificio del patrimonio de la ciudad el $87 \%$ contestó que sí.

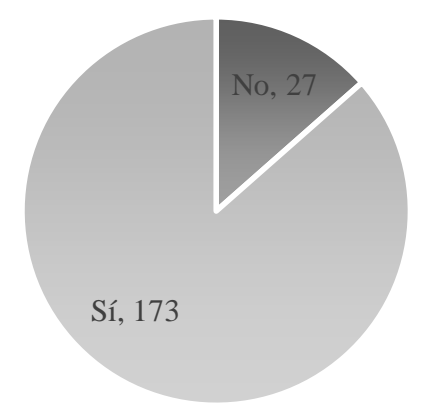

Figura 1. Conocimiento sobre edificaciones históricas en San Pedro Sula

Fuente: Elaboración Propia

Pregunta 2: ¿Cuáles conoce de estos edificios?

De los informantes que dijeron conocer un edificio histórico, el más conocido es el del Ferrocarril Nacional con un $70 \%$ de la muestra, seguido por los dos museos de la ciudad, solo el $3 \%$ dijo conocer "otros".

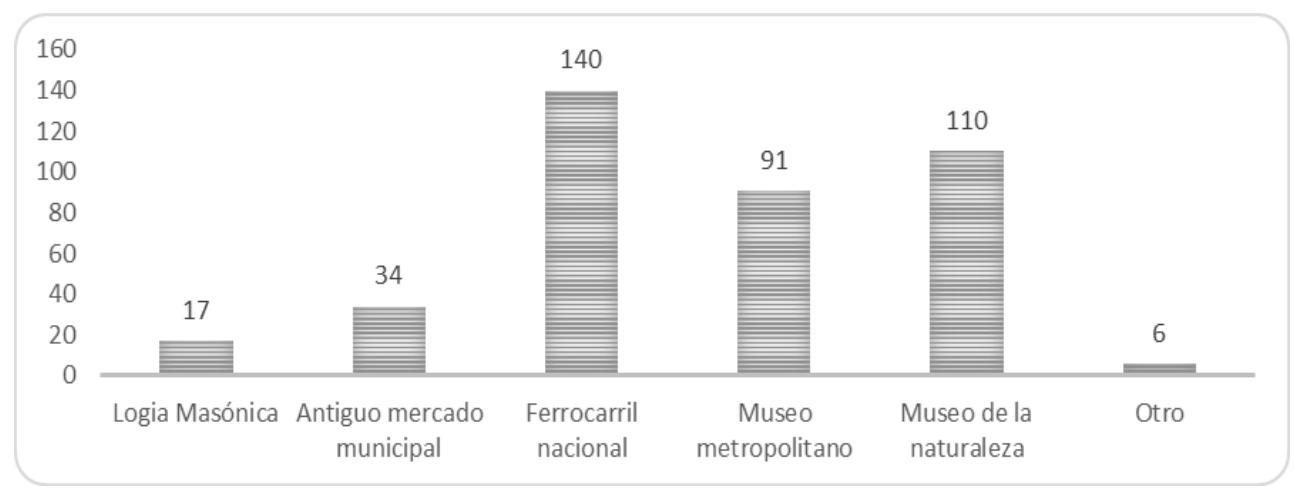

Figura 2. Conocimiento sobre edificaciones históricas específicas de San Pedro Sula

Fuente: Elaboración Propia

Pregunta 3 ¿Existe algún elemento del pasado que le gustaría recuperar en la ciudad de San Pedro Sula?

Para explorar el conocimiento de los informantes sobre el patrimonio de la ciudad, se realiza esta pregunta, solo el $56 \%$ contestó que sí había elementos del pasado para recuperar. 


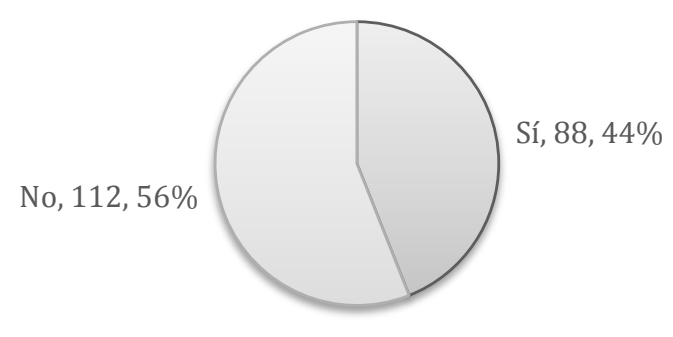

Figura 3. Deseo de recuperar elementos del patrimonio histórico de la ciudad de San Pedro Sula

Fuente: Elaboración Propia

Pregunta 4: ¿Qué elemento del pasado le gustaría recuperar?

$\mathrm{Al}$ indagar que es lo que quieren que se recupere, la mayoría dice que el Ferrocarril Nacional, con un $63 \%$.

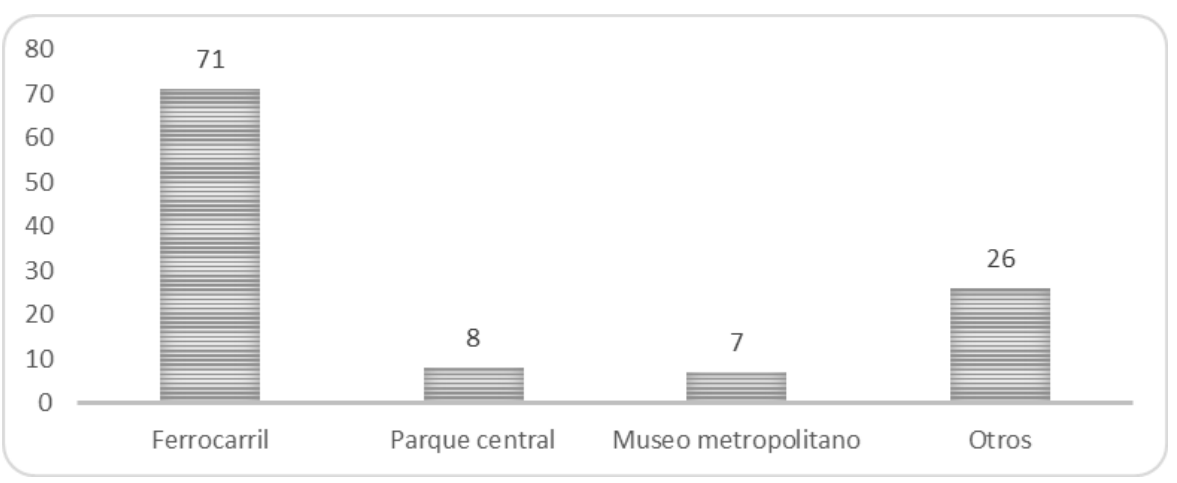

Figura 4. Elementos del patrimonio histórico de la ciudad de San Pedro Sula que deberían ser recuperados

Fuente: Elaboración Propia

Pregunta 5: ¿Qué sugerencia urbana se le ocurre para recuperar una Zona Típica de la ciudad?

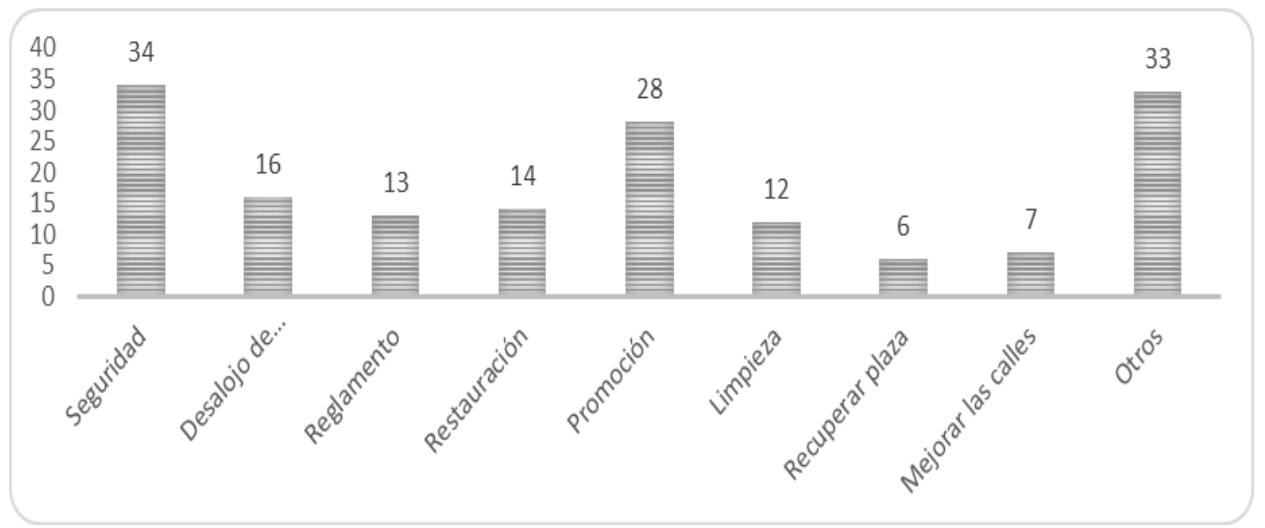

Figura 5. Posibles acciones a tomar para recuperar la zona típica de la ciudad

Fuente: Elaboración Propia 
El $20 \%$ de los sampedranos se preocupan por la seguridad, el $17 \%$ considera que se necesita más promoción del patrimonio del centro de la ciudad, seguido de muchas otras iniciativas que consideran que se deben tomar.

Pregunta 6: ¿Qué sugerencia de actividades se le ocurre para recuperar una Zona Típica de la ciudad? El 24\% de los encuestados quiere ferias, seguido de exposiciones, con un $14 \%$.

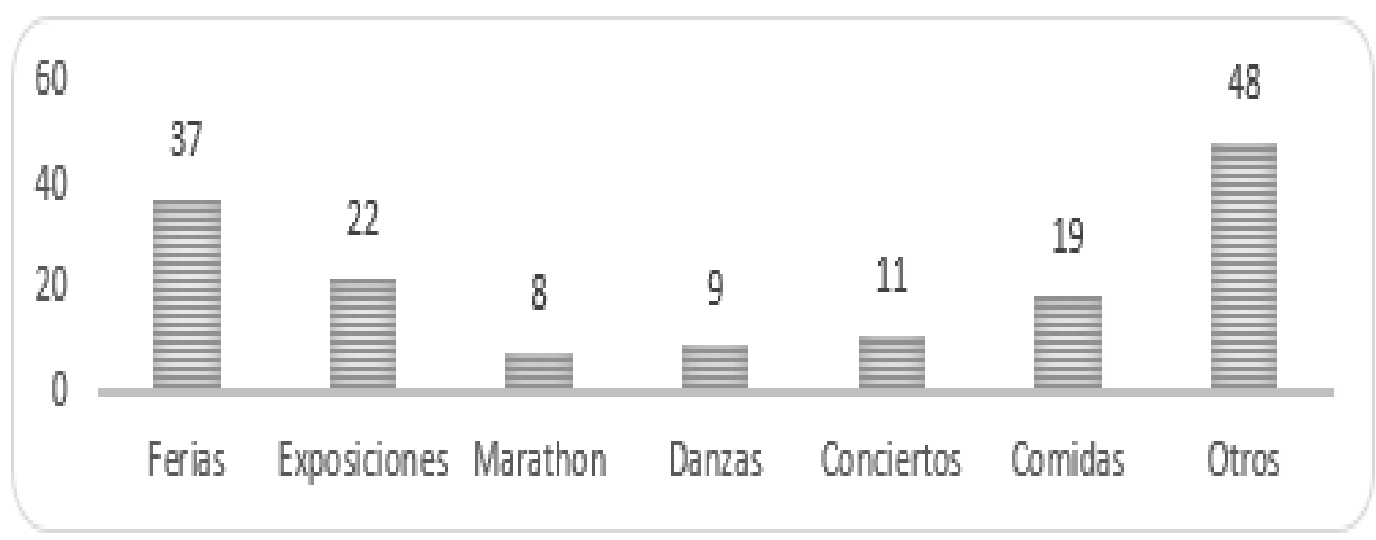

Figura 6. Posibles actividades para recuperar la zona típica de la ciudad

Fuente: Elaboración Propia

Pregunta 7: ¿Qué sectores de la ciudad le gustaría recuperar turísticamente?

La mayoría de los informantes considera que se debe recuperar el parque central, seguido del mercado Guamilito $42 \%$.

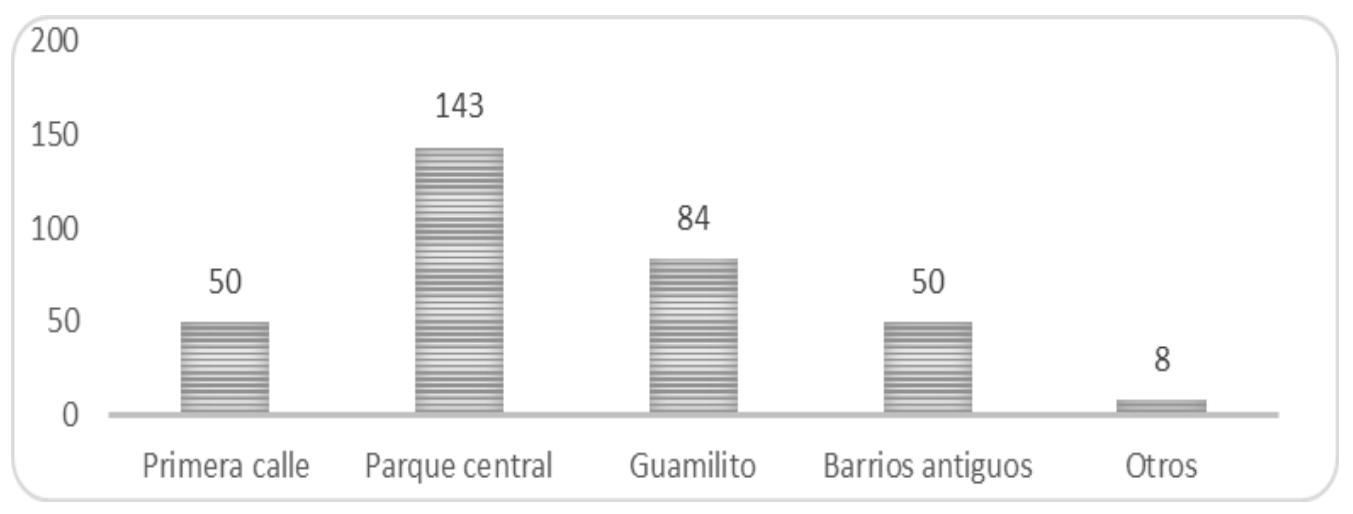

Figura 7. Sectores de la ciudad que deben ser recuperados prioritariamente

Fuente: Elaboración Propia

Sexo: $65 \%$ de los informantes pertenecen al sexo femenino. 


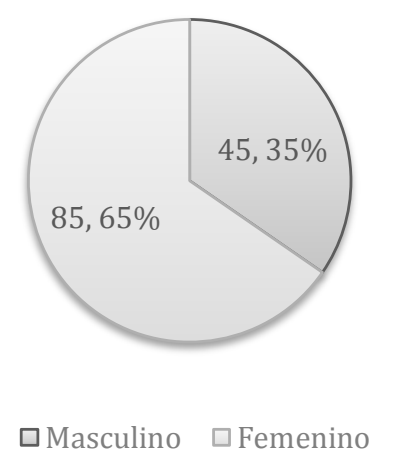

Figura 8. Género de los informantes

Fuente: Elaboración Propia

Zona de residencia: La mayoría de los informantes reside en el sector noroeste, el de mayor crecimiento en la ciudad.

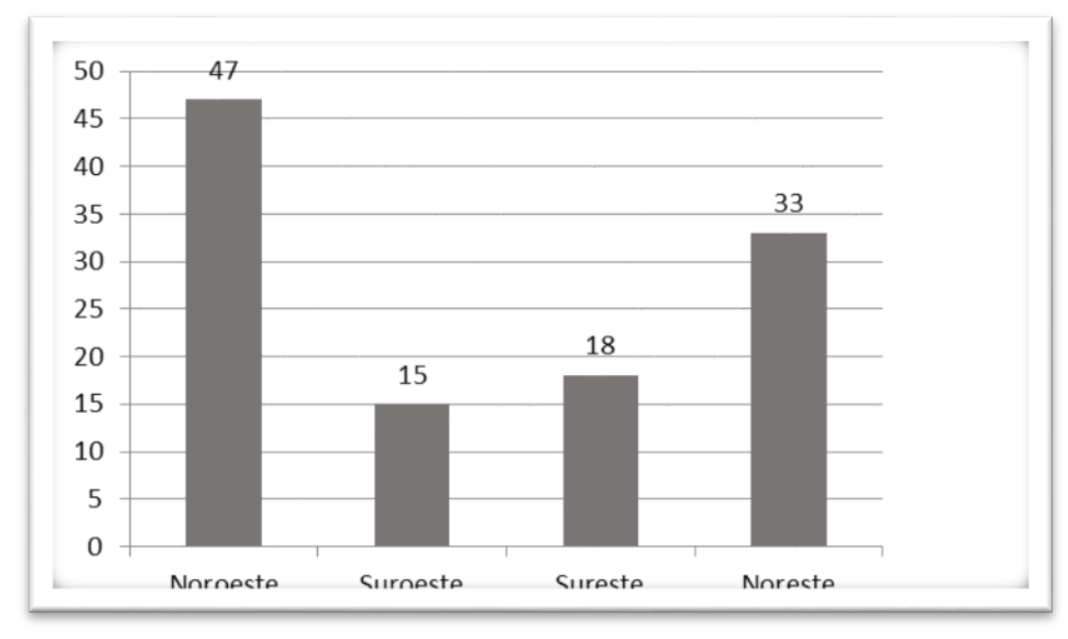

Figura 9. Sector de la ciudad en el que residen los informantes

Fuente: Elaboración Propia

\subsubsection{Cruces de variables}

I. Al cruzar zona de residencia con el conocimiento de algún edificio del patrimonio de la ciudad, se observan valores de Phi y V de Cramer de 0.15 cercanos a 0 por lo cual se concluye, que no hay asociación entre zona de residencia y conocimiento del patrimonio de la ciudad. 
Tabla 4: Asociación entre el lugar de residencia del informante y el conocimiento de edificios que integran el patrimonio histórico de la ciudad

\begin{tabular}{|c|c|c|c|}
\hline \multirow{2}{*}{ CRUCE I } & \multicolumn{2}{|c|}{$\begin{array}{c}\text { ¿Conoce algún edificio del } \\
\text { patrimonio histórico de San }\end{array}$} & \multirow{2}{*}{ Total } \\
\cline { 2 - 3 } & Si & No & \\
\hline Noroeste & 36 & 2 & 47 \\
\hline Suroeste & 13 & 2 & 15 \\
\hline Sureste & 16 & 2 & 18 \\
\hline Noreste & 29 & 4 & 33 \\
\hline Total & 94 & 19 & 113 \\
\hline
\end{tabular}

\begin{tabular}{|l|c|}
\hline & Valor \\
\hline Chi-cuadrado de Pearson & $2.527(\mathrm{a})$ \\
\hline Phi & 0.15 \\
\hline V de Cramer & 0.15 \\
\hline
\end{tabular}

Fuente: Elaboración Propia

II. Al cruzar zona de residencia con el deseo de recuperar algún elemento del pasado de la ciudad, se observan valores de Chi cuadrado que indican que no hay asociación entre zona de residencia y deseo de recuperar algún elemento del pasado de la ciudad.

Tabla 5: Asociación entre el lugar de residencia del informante y el deseo de recuperar el patrimonio histórico de la ciudad

\begin{tabular}{|c|c|c|c|}
\hline \multirow{2}{*}{ CRUCE ॥ } & \multicolumn{2}{|c|}{$\begin{array}{c}\text { ¿Existe algún elemento del pasado de San } \\
\text { Pedro Sula que le gustaría recuperar? }\end{array}$} & \multirow{2}{*}{ Total } \\
\hline & Sí & No & \\
\hline \multicolumn{4}{|l|}{ Reside } \\
\hline Noroeste & 24 & 23 & 47 \\
\hline Suroeste & 7 & 8 & 15 \\
\hline Sureste & 13 & 5 & 18 \\
\hline Noreste & 16 & 17 & 33 \\
\hline Total & 60 & 53 & 113 \\
\hline
\end{tabular}

\begin{tabular}{|l|l|}
\hline & Valor \\
\hline Chi-cuadrado de Pearson & 3.253 (a) \\
\hline \multirow{2}{*}{ Nominal por nominal } & Phi \\
\cline { 2 - 2 } & V de Cramer \\
\hline
\end{tabular}

Fuente: Elaboración Propia

III. Al cruzar el sexo de la persona con el conocimiento de algún edificio del patrimonio de la ciudad, se observan valores de Chi cuadrado que indican, que no hay asociación entre el género de los informantes y conocimiento del patrimonio de la ciudad.

Tabla 6: Asociación entre el género de los informantes y el conocimiento que poseen sobre el patrimonio histórico de la ciudad

\begin{tabular}{|l|r|r|r|}
\hline \multirow{2}{*}{ Cruce III } & \multicolumn{2}{|c|}{$\begin{array}{c}\text { ¿Conoce algún edificio del patrimonio } \\
\text { histórico de San Pedro Sula? }\end{array}$} & \multirow{2}{*}{ Total } \\
\cline { 2 - 3 } & Sí & No & \\
\hline Sexo & 40 & 5 & 45 \\
\hline Masculino & 70 & 15 & 85 \\
\hline Femenino & 110 & 20 & 130 \\
\hline Total & \multicolumn{2}{|c|}{} \\
\hline
\end{tabular}

\begin{tabular}{|l|l|}
\hline & Valor \\
\hline Chi-cuadrado de Pearson & $.966(\mathrm{~b})$ \\
\hline Nominal por nominal & Phi \\
\cline { 2 - 2 } & V de Cramer \\
\hline
\end{tabular}

Fuente: Elaboración Propia 
IV. Al cruzar el sexo de la persona con el deseo de recuperar algún elemento del pasado de la ciudad, se observan valores de Phi y V de Cramer cercanos a 0 por lo cual se concluye, que no hay asociación entre el género del informante y su deseo de recuperar el patrimonio histórico de la ciudad.

Tabla 7: Asociación entre el género del informante y su deseo de recuperar el patrimonio histórico de la ciudad

\begin{tabular}{|c|c|c|c|c|}
\hline \multirow{2}{*}{\multicolumn{2}{|c|}{ CRUCE IV }} & \multicolumn{2}{|c|}{$\begin{array}{l}\text { ¿Existe algún elemento del pasado de San } \\
\text { Pedro Sula que le gustaría recuperar? }\end{array}$} & \multirow[t]{2}{*}{ Total } \\
\hline & & Si & No & \\
\hline & Masculino & 24 & 21 & 45 \\
\hline & Femenino & 47 & 38 & 85 \\
\hline \multicolumn{2}{|l|}{ Total } & 71 & \begin{tabular}{l|l}
59 \\
\end{tabular} & 130 \\
\hline & Valor & gl & Sig. asintótica (bilateral) & \\
\hline Chi-cuadrado & .046 (b) & 1 & 0,831 & \\
\hline \multirow{2}{*}{$\begin{array}{l}\text { Nominal por } \\
\text { nominal }\end{array}$} & Phi & $-0,019$ & 0,831 & \\
\hline & V de Cramer & 0,019 & 0,831 & \\
\hline
\end{tabular}

Fuente: Elaboración Propia

\subsection{Resultados entrevistas exhaustivas}

\subsubsection{Entrevistas con expertos ${ }^{2}$}

Pregunta 1: De los 7 entrevistados 6 coinciden en que, sí existe un patrimonio histórico significativo en San Pedro Sula, uno considera que: "No, lo poco que queda está destruido y en el abandono, no hay una institución encargada de protegerlo".

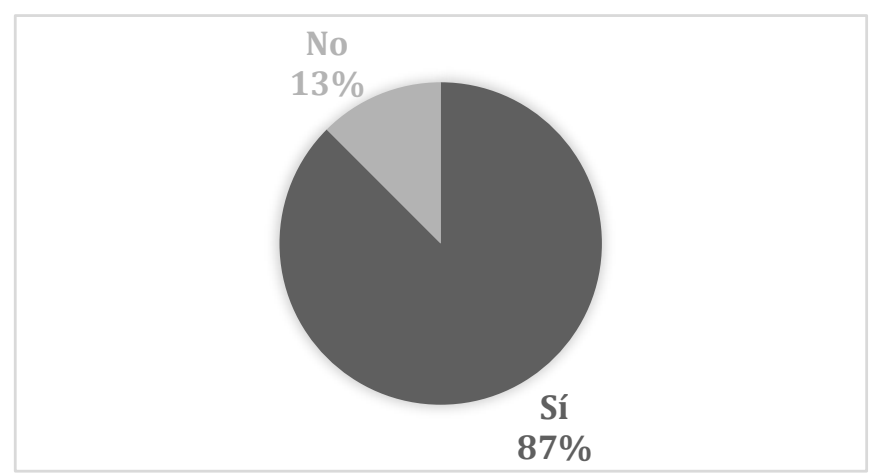

Figura 10: Opinión de expertos sobre la existencia de patrimonio histórico significativo en San Pedro Sula

Fuente: Elaboración Propia

\footnotetext{
${ }^{2}$ Los expertos entrevistados son: Viena Sloan Martínez, Arquitecto; Fabiola Fúnez Núñez, Arquitecto; Ana Lucía Barahona, Arquitecto; René Chinchilla, Arquitecto; Miliser Delgado, Arquitecto; Ángela Stassano, Arquitecto; y, Rosa Elena de Pastor, Directora del Museo de Antropología e Historia de San Pedro Sula.
} 
Pregunta 2: Los entrevistados señalaron la catedral, el museo y Parque Central como símbolos del patrimonio, en contraposición al público general que se identificó más con el ferrocarril nacional.

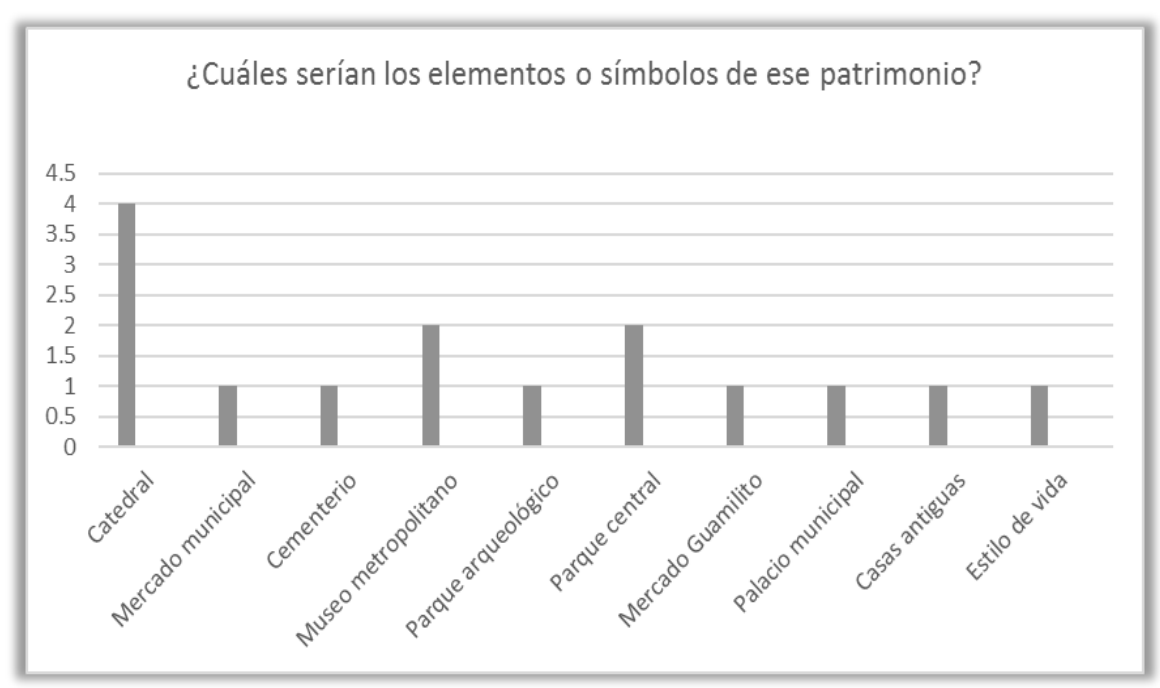

Figura 11: Opinión de expertos sobre los elementos que deberían integrar el patrimonio histórico de San Pedro Sula

Fuente: Elaboración Propia

Pregunta 3: De los 7 entrevistados, 3 señalan la importancia de recuperar las casas de madera del centro de la ciudad.

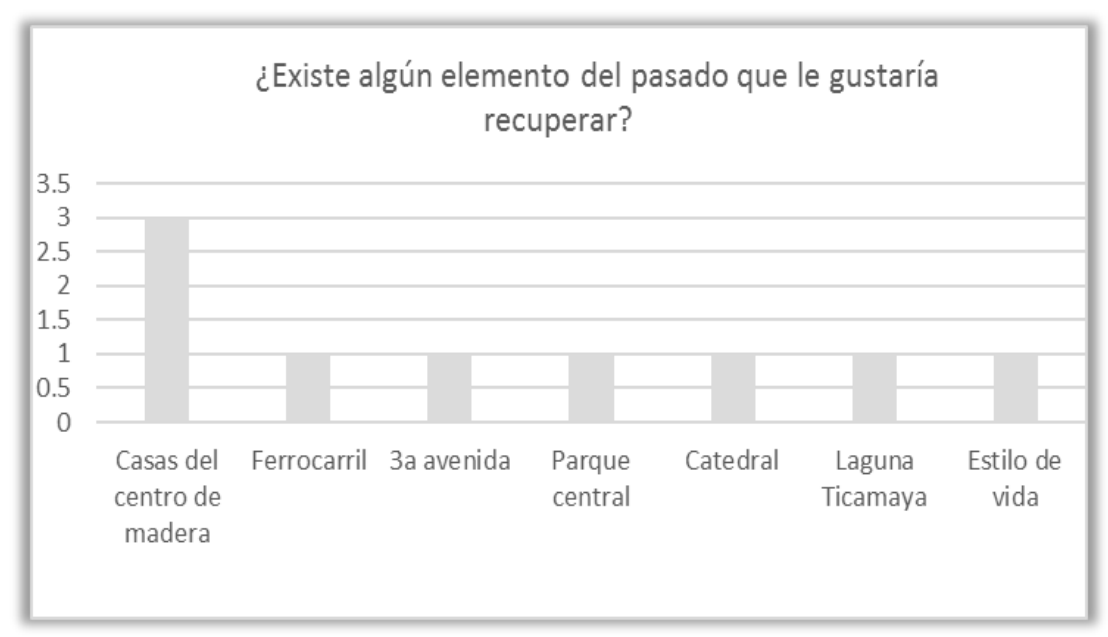

Figura 12: Opinión de expertos sobre los elementos que deberían recuperarse como parte del patrimonio histórico de San Pedro Sula

Fuente: Elaboración Propia

Pregunta 4: Según las entrevistas el instrumento idóneo para lograr la protección de estos elementos es la ley para el patrimonio histórico cuyo organismo ejecutante es el IHAH, 2 mencionan las ordenanzas municipales, pero no hay evidencia de ello en la bibliografía recopilada. 


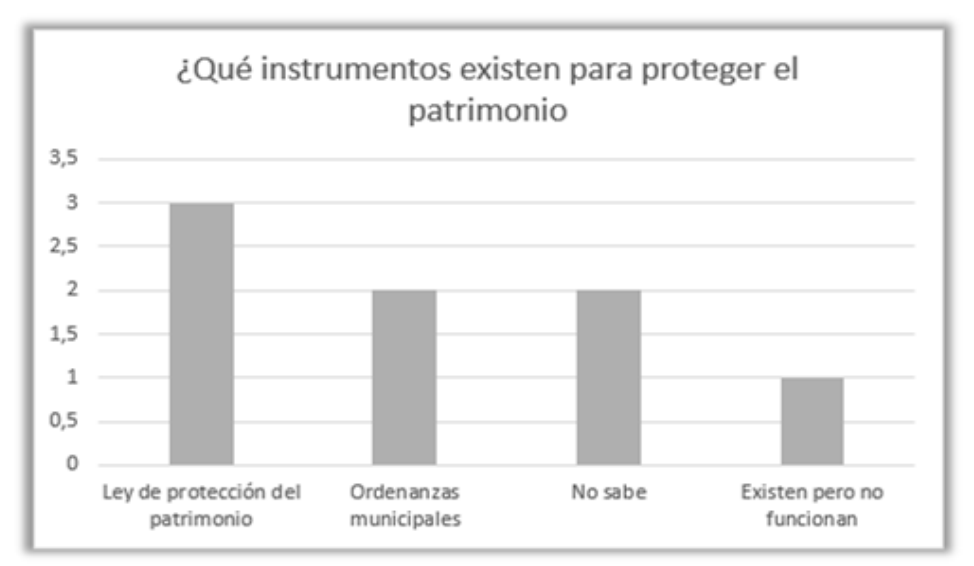

Figura 13: Opinión de expertos sobre los instrumentos idóneos para lograr la protección adecuada del patrimonio histórico de San Pedro Sula

Fuente: Elaboración Propia

Pregunta 5: Cinco de los entrevistados considera que sí existe un casco histórico en la ciudad de San Pedro Sula.

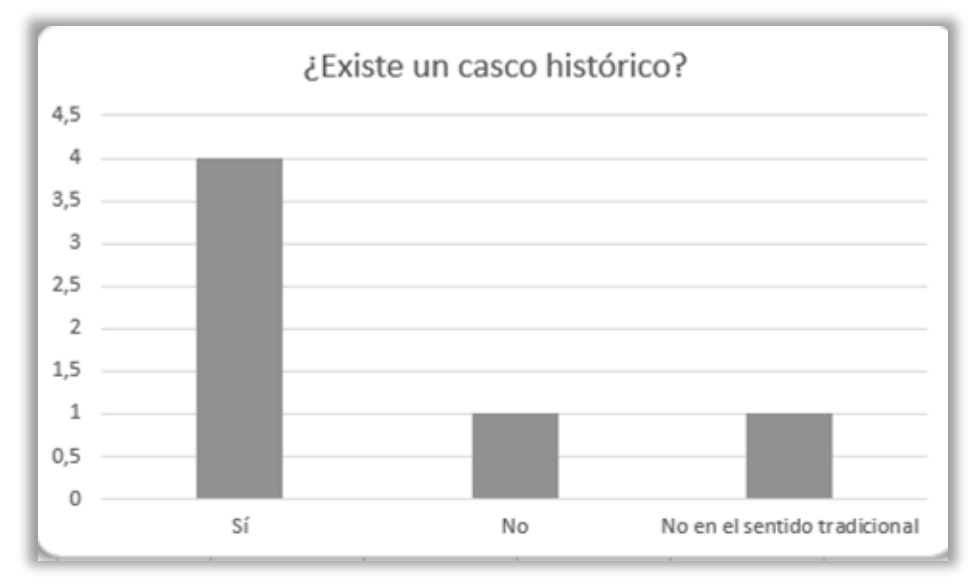

Figura 14: Opinión de expertos sobre la existencia de un casco histórico en San Pedro Sula

Fuente: Elaboración Propia

Pregunta 6: No hay consenso con respecto a los límites de un casco histórico en San Pedro Sula, pero la mayoría de los entrevistados coinciden en la 1 calle 3 avenida y algunos barrios históricos como parte de un conjunto histórico. 


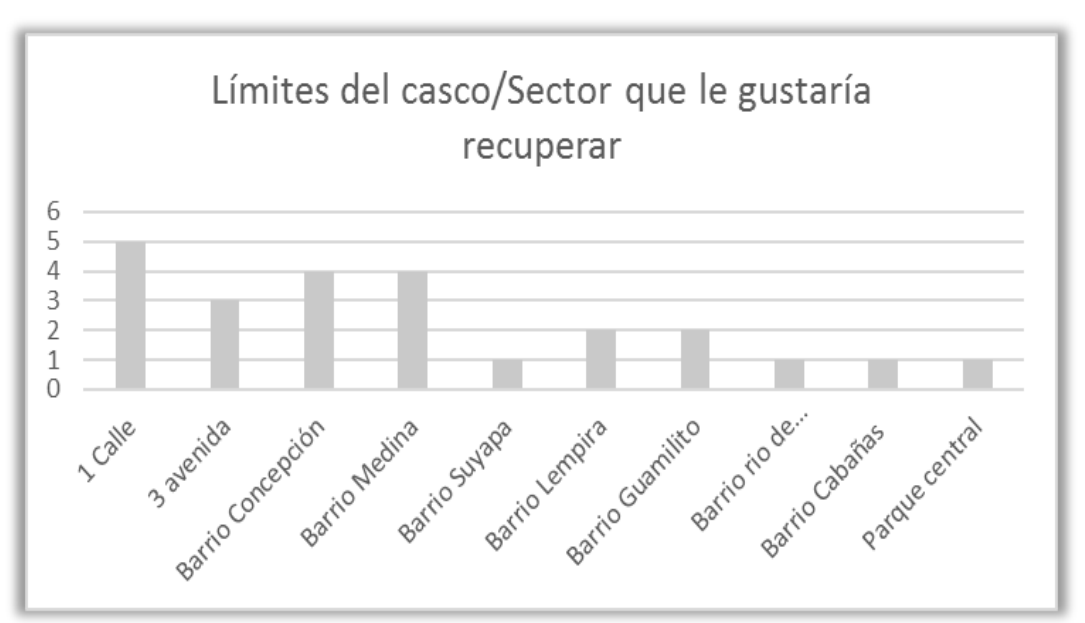

Figura 15: Opinión de expertos sobre los límites del casco histórico en San Pedro Sula

Fuente: Elaboración Propia

\subsubsection{Entrevistas a profundidad a ciudadanos}

Pregunta 1: ¿Tiene San Pedro Sula un patrimonio histórico significativo? 5 de los entrevistados coinciden en que, San Pedro Sula, sí posee un patrimonio histórico significativo.

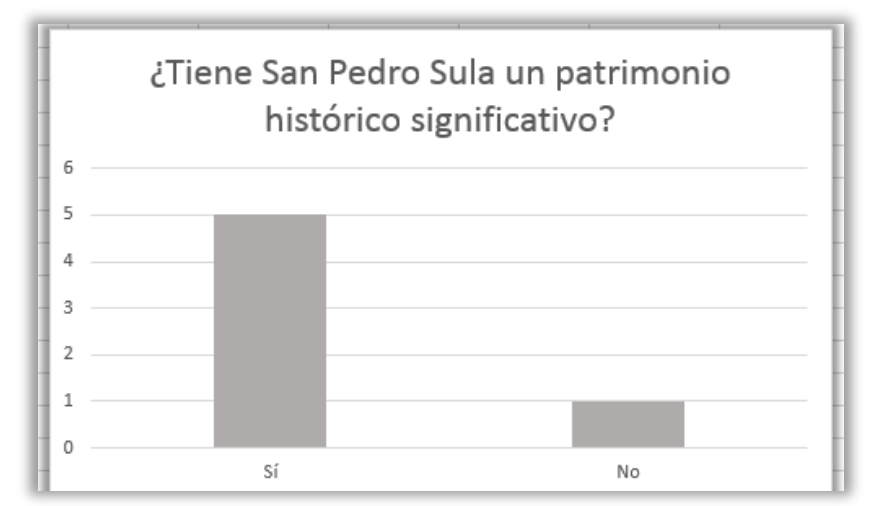

Figura 16: Opinión de la ciudadanía sobre la existencia de un patrimonio histórico significativo en San Pedro Sula

Fuente: Elaboración Propia

Pregunta 2: ¿Cuáles serían los elementos o símbolos de ese patrimonio? En este caso la mayoría de los entrevistados señalaron a la catedral como referente de este patrimonio. 


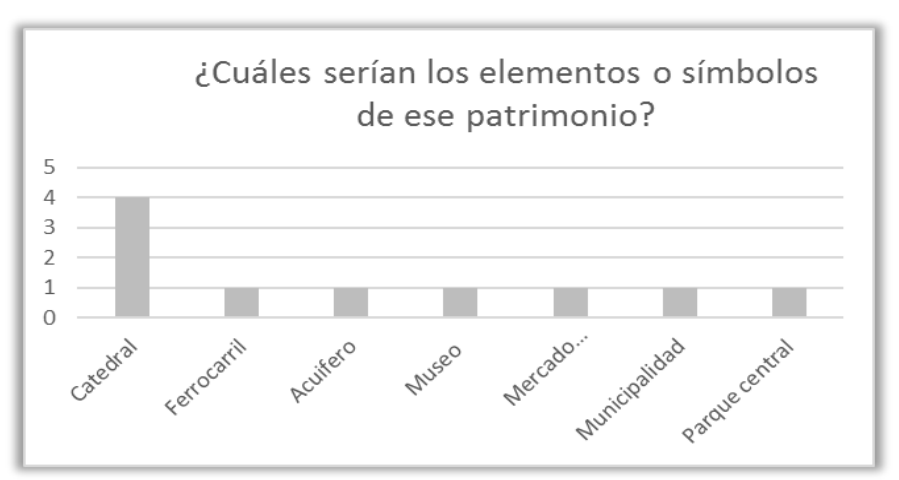

Figura 17: Opinión de la ciudadanía sobre los elementos que forman parte del patrimonio histórico significativo en San Pedro Sula

Fuente: Elaboración Propia

Pregunta 3: ¿Existe algún elemento del pasado que le gustaría recuperar? Los entrevistados coincidieron en la recuperación del ferrocarril nacional.

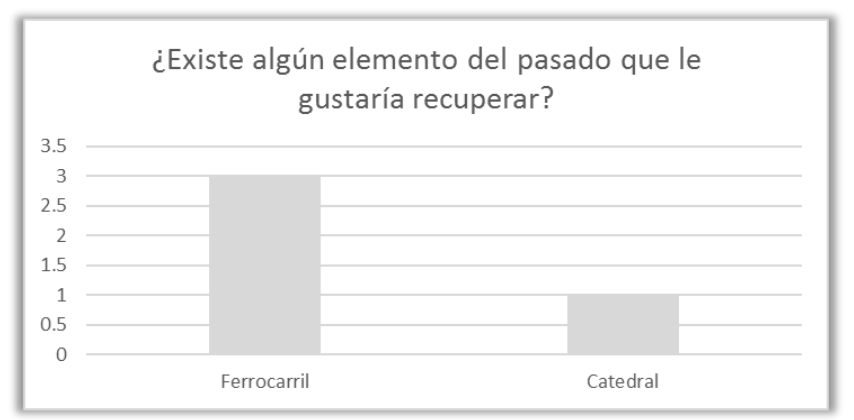

Figura 18: Opinión de la ciudadanía sobre los elementos del patrimonio histórico significativo en San Pedro Sula que deben recuperarse

Fuente: Elaboración Propia

Pregunta 4: ¿Qué reglamento existe para proteger el patrimonio? En este aspecto los informantes no conocen de reglamentos para proteger el patrimonio de la ciudad, solo uno mencionó la Ley de Protección del Patrimonio Histórico.

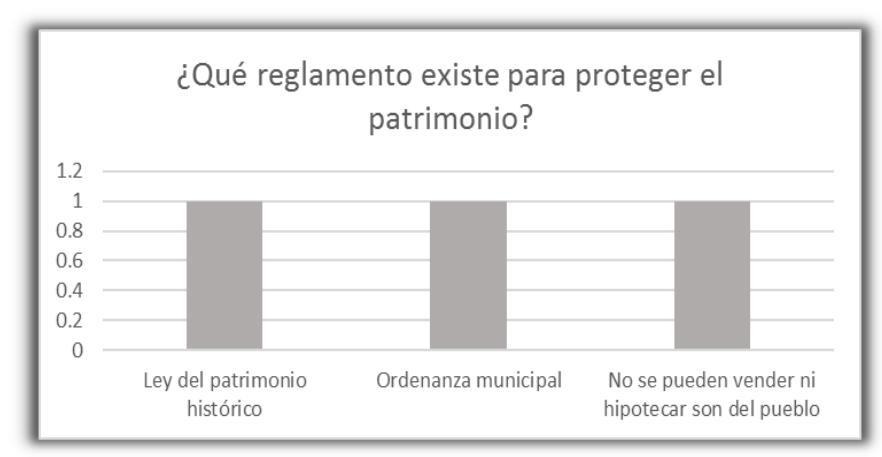

Figura 19: Opinión de la ciudadanía sobre el mecanismo idóneo para proteger el patrimonio histórico significativo en San Pedro Sula

Fuente: Elaboración Propia 
Pregunta 5: ¿Podemos hablar de un casco histórico? Los informantes mostraron opiniones divididas con respecto a la existencia o no de un casco histórico.

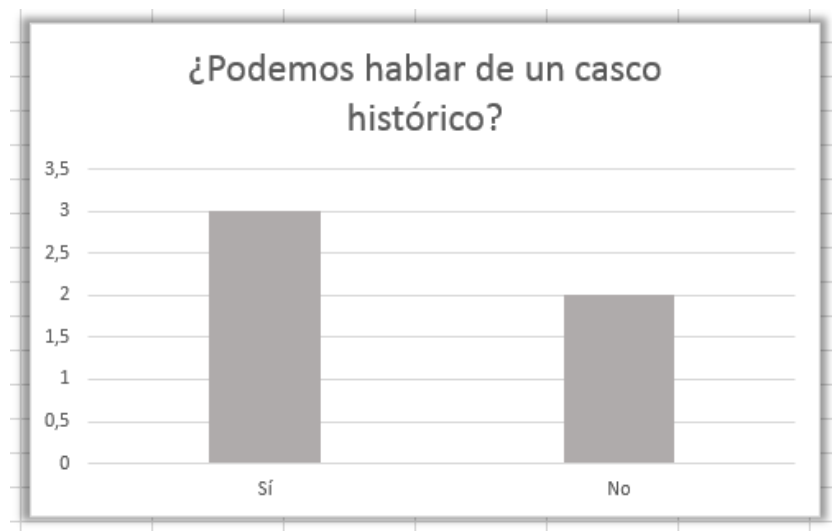

Figura 20: Opinión de la ciudadanía sobre la existencia de un casco histórico en San Pedro Sula

Fuente: Elaboración Propia

Pregunta 6: Límites del casco/Sector que le gustaría recuperar. Al igual que en las entrevistas con expertos, en la entrevista con ciudadanos de la tercera edad, se coincide en el sector de la 1 calle y 3 avenida.

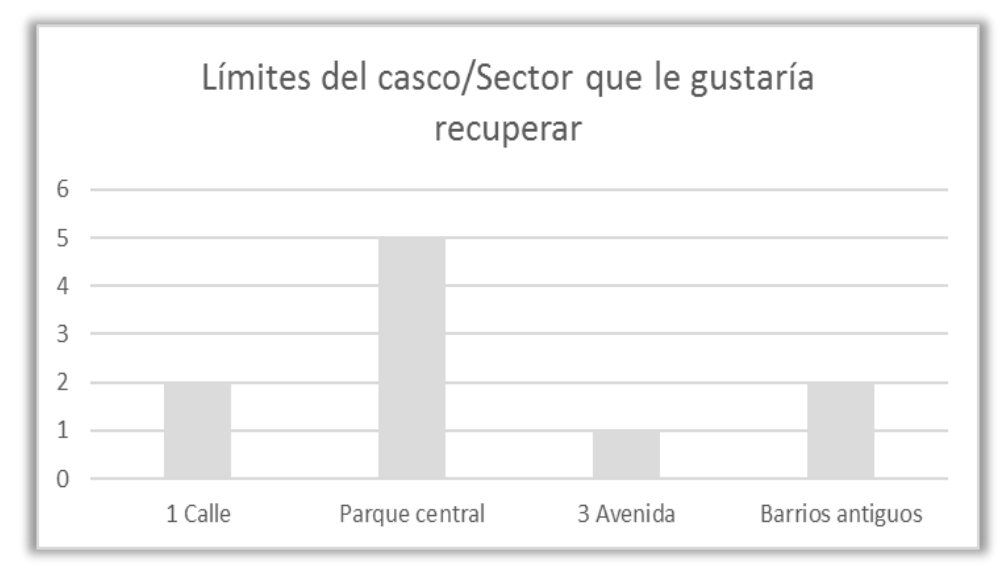

Figura 21: Opinión de la ciudadanía sobre los sectores donde se ubica el patrimonio histórico significativo en San Pedro Sula que debería ser recuperado

Fuente: Elaboración Propia

Pregunta 7: Barrios históricos. Los informantes brindan una selección más amplia que en la entrevista con expertos, pero coinciden en la importancia del sector Guamilito. 


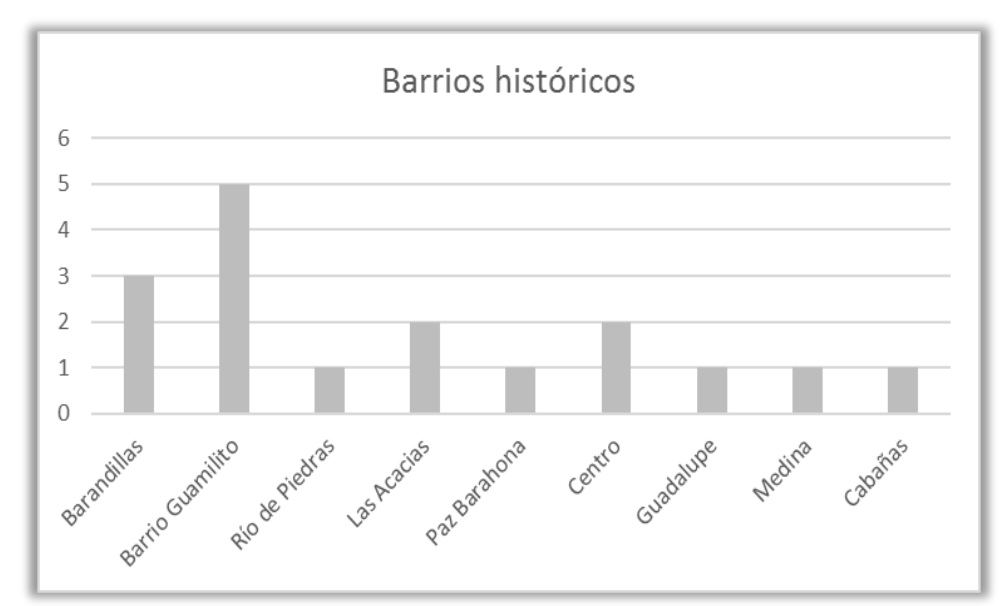

Figura 22: Opinión de la ciudadanía sobre los barrios históricos de San Pedro Sula Fuente: Elaboración Propia

\section{Conclusiones}

1. Al consultarle a los informantes si conocen un edificio del patrimonio de la ciudad el $87 \%$ contestó que sí.

2. De los informantes que dijeron conocer un edificio histórico el más conocido es el del Ferrocarril Nacional con un $70 \%$ de la muestra, seguido por los dos museos de la ciudad, solo el 3\% dijo conocer "otros".

3. Para explorar el conocimiento de los informantes sobre el patrimonio de la ciudad, se realiza esta pregunta 3, el 56\% contestó que sí había elementos del pasado para recuperar.

4. Al indagar que es lo que quieren que se recupere, la mayoría dice que el Ferrocarril Nacional con un $63 \%$.

5. El $20 \%$ de los sampedranos se preocupan por la seguridad, el $17 \%$ considera que se necesita más promoción del patrimonio del centro de la ciudad, seguido de muchas otras iniciativas que consideran que se deben tomar.

6. El $24 \%$ de los encuestados quiere ferias, seguido de exposiciones con un $14 \%$ a continuación una variedad de actividades que se desglosan en la sección de tablas en anexos.

7. La mayoría de los informantes considera que se debe recuperar el parque central, seguido del mercado Guamilito $42 \%$.

8. La mayoría de los informantes reside en el sector noroeste, el de mayor crecimiento en la ciudad.

9. Los entrevistados coinciden en que San Pedro Sula sí posee un patrimonio histórico significativo.

10. No hay consenso con respecto a los límites de un casco histórico en San Pedro Sula, pero la mayoría de los entrevistados coinciden en la 1 calle 3 avenida y algunos barrios históricos como parte de un conjunto histórico.

11. Los entrevistados señalaron la catedral, el museo y Parque Central como símbolos del patrimonio, en contraposición al público general que se identificó más con el ferrocarril nacional. 
12. Al cruzar zona de residencia con el conocimiento de algún edificio del patrimonio de la ciudad, se observan valores de Phi y V de Cramer menores a de 0.15 cercanos a 0 por lo que se concluye, que no hay asociación entre zona de residencia y conocimiento del patrimonio de la ciudad.

13. Al cruzar zona de residencia con el deseo de recuperar algún elemento del pasado de la ciudad, se observan valores de Chi cuadrado que indican, que no hay asociación entre zona de residencia y deseo de recuperar algún elemento del pasado de la ciudad.

14. Al cruzar el sexo de la persona con el conocimiento de algún edificio del patrimonio de la ciudad, se observan valores de Chi cuadrado que indican, que no hay asociación entre sexo de la persona y conocimiento del patrimonio de la ciudad.

15. Al cruzar el sexo de la persona con el deseo de recuperar algún elemento del pasado de la ciudad, se observan valores de Phi y V de Cramer cercanos a 0 por lo cual se concluye, que no hay asociación entre sexo de la persona y conocimiento del patrimonio de la ciudad.

\section{Bibliografía}

Aas, C., Ladkin, A., y Fletcher, J. (2004). Stakeholder collaboration and heritage management.

Recuperado de http://eprints.bournemouth.ac.uk/105/1/Fletcher_Output_4.pdf

Ballart, J. (1997). El patrimonio histórico y arqueológico: valor y uso. Barcelona, España: Editorial Planeta.

DIEM (2014). Sistema de Indicadores Socio-Demográficos San Pedro Sula. Recuperado el 16 de 01 de $2015, \quad$ de DIEM: http://www.infohn.com/sisde/home.htm

Geser, G. (2012). Creative cooperation in cultural heritage. Salzburg Research Centre. Forschungsgesellschaft mbH,

Guerrero, R. (2011). Patrimonio cultural mundial, territorio y construcción de ciudadanía, construcción y apropiación social del patrimonio cultural de la ciudad de Valparaíso-Chile. Scripta Nova, Revista Electrónica de geografía y Ciencias Sociales, 168(15), 90.

López, E. M. (2010). Conservación del patrimonio edificado y políticas públicas: del concepto a la práctica en el estado de Michoacán. Revista de Investigación Científica en Arquitectura, 5(2), 15-26.

Mirpour, K. (2012). Remapping of attentional priority across the entire visual field. Journal of Vision, 12(9), 215.

Moreno, O. M. (2012). Educación y Patrimonio. Ciudad de México, México: Editorial de la Universidad Nacional Autónoma de México. 
Olsson, K. (2008). Citizen input in urban heritage management and planning a quantitative approach to citizen participation. Town Planning Review, 79(4), 371-394.

Puig, T. (2008). Marca ciudad o como rediseñarla para asegurar un futuro espléndido para todos. (Vol. 143). Gurpo Planeta.

Reus, P. (2014). Conservación del patrimonio construido, acción ciudadana y redefinición disciplinar La Tabacalera de Lavapiés - La Casa Invisible de Málaga. Investigación e innovación en arquitectura y territorio, 1(2)

Schiffman, L. G., y Kanuk, L. L., (2014). Consumer Behavior. New Yor, New York: Paperback.

Shipley, R., y Kovacs, J. F. (2007). Good governance principles for the cultural heritage sector: lessons from international experience. Corporate Governance: The international journal of business in society, 8(2), 214-228.

Stassano, A. (1997). Adobe, madera y ladrillo en la arquitectura de San Pedro Sula. Un vistazo actual a la arquitectura creada entre 1900-1950 (1 ed.). Tegucigalpa, Francisco Morazán, Honduras: Transamérica.

Tweed, C., \& Sutherland, M. (2007). Built Cultural Heritage and Sustainable Urban Development. Landscape and Urban Planning, 83(1), 62-69.

Zetti, I. (2010). Built heritage in social and economic development integrating aimsbuilt heritage, local communities and the production of territory. Citizen participation in heritage preservation and improvement. Centre for urban and regional studies publications, 231. 